\title{
Влияние природно-климатических условий на популяции ли- шайника Physcia stellaris (L.) Nyl.
}

\author{
(C) 3.P. Саитова \\ Башкирский государственный университет \\ Россия, Республика Башкортостан, 450076 г. Уфра, улица Заки Валиди, 32.

\section{Email: fleurzily@yandex.ru}

Для оценки влияния природно-климатических условий на популяции лишайника Physcia stellaris (L.) Nyl. произрастающие в различных природных зонах (горно-лесной и лесостепной) был проведен анализ морфометрических показателей лишайника (масса, длина, площадь таллома, число апотеций и лопастей), размера его составляющих компонентов (фото- и фритобионт), а также определено содержание фритогормонов. Проведен анализ количественного и качественного состава соединений фенольной природы в лишайниках, внесших вклад в формирование общего антиоксидантного статуса.

Ключевые слова: лишайники, фритогормоны, фрлавоноиды, антиоксидантный статус

Лишайники являются частью любой экосистемы. Они способны выживать в экстремальных условиях среды. На жизненные процессы любого организма оказывают влияние как абиотические, биотические так и антропогенные фракторы. Лишайники особенно чувствительны к изменениям среды. На их рост и развитие оказывают влияние все фракторы среды как природные, так и антропогенные, приводя либо к угнетению ростовых и фризиологических процессов, либо наоборот прогрессивному росту и развитию [1].

Цель работы определить влияние природно-климатических условий на популяции лишайника Physcia stellaris (L.) Nyl. произрастающие в различных природных зонах. A именно горно-лесной и лесостепной зонах.

Исследования популяций лишайника Physcia stellaris (L.) Nyl. проводились в Ишимбайском (горно-лесная зона) и Альшеевском (лесостепная) районах Республики Башкортостан.

Проанализировав морфометрические показатели лишайников популяции $P$. stellaris на разных этапах онтогенеза, произрастающих в данных исследуемых районах (Ишимбайском и Альшеевском) значимых различий между анализируемыми показателями не выявлено (табл.1) Такое незначительное различие в морфометрических параметрах возможно связано с условиями обитания лишайников. Ведь как видно из таблицы 1 по показателям освещенности и влажности воздуха, наиболее освещенными и отностительно влажными, являются леса Ишимбайского района по сравнению с лесами Альшеевского района.

Лишайники имеют способность аккумулировать в талломе различные вещества. И так как они чувствительны к содержанию в атмосфере соединений серы нами был проведен анализ содержания оксида серы (VI) в талломе лишайника P. stellaris. Как показано 
в таблице 1, процентное содержание оксида серы (VI) в образцах лишайников, собранных в исследуемых районах, было почти одинаковое и отличается всего лишь на $0,02 \%$ масс.

Таким образом, природно-климатические зоны приводят к сложению определенных условий (освещенность, влажность и т.д.) для формирования популяций $P$. stellaris и наиболее благоприятными условия для роста лишайников имелись в условиях горнолесной зоны.

Таблица.1 Морфометрические показатели ценопопуляций Physcia stellaris (L.)Nyl. произрастающих в разных природных зонах

\begin{tabular}{|l|c|c|}
\hline \multirow{2}{*}{ Показатели } & \multicolumn{2}{|c|}{ Место сбора } \\
\cline { 2 - 3 } & Альшеевский район & Ишимбайский район \\
\hline Биомасса, г & $0,15 \pm 0,06$ & $0,12 \pm 0,05$ \\
\hline Длина, мм & $15,8 \pm 2,5$ & $16,4 \pm 3,4$ \\
\hline Площадь, мм & $168,1 \pm 16,5$ & $161,2 \pm 18,3$ \\
\hline Число апотециев, шт & $87,1 \pm 8,9$ & $84,3 \pm 11,4$ \\
\hline Число лопастей & $31,0 \pm 1,9$ & $33,1 \pm 2,1$ \\
\hline $\begin{array}{l}\text { Содержание воды в сырых лишайни- } \\
\text { ках, \% }\end{array}$ & $20,3 \pm 2,46$ & $46,4 \pm 6,02$ \\
\hline Снижение освещенности,$\%$ & $62 \pm 2,2$ & $78 \pm 1,9$ \\
\hline $\begin{array}{l}\text { Повышение относительной влажности } \\
\text { воздуха }{ }^{* * *}, \%\end{array}$ & $6 \pm 1$ & $8 \pm 2$ \\
\hline Содержание $\mathrm{SO}_{3}, \%$ масс & $1,31 \pm 0,04$ & $1,29 \pm 0,04$ \\
\hline
\end{tabular}

*различия между образцами районов достоверны при $P \leq 0,05$

** разница между освещенностью под пологом леса и открытого места

*** разница между относительной влажностью воздуха под пологом леса и открытого места в безветренную погоду

Все фризиологические процессы (рост, развитие, старение и т.д.) в растениях контролируются фритогормонами. Определено, что они осуществляют регуляцию последовательности всех этапов развития растений, а также их ответную реакцию на внешние воздействия на генетическом уровне. Особенно важными среди них являются ауксин (ИУК), абсцизовая кислота (АБК) и цитокинины, т.к. они выполняют ключевую роль в развитии растений [2]. Значимую роль данные фитогормоны выполняют и в грибковых симбиозах, таких как микориза. Фитогормоны, выделяемые корнями растений, влияют на метаболизм и рост микоризных грибов, а фитогормоны грибного происхождения влияют на морфологию, метаболизм и рост растения [3].

Роль фитогормонов в этапах развития лишайников мало известна [4]. Это связано с тем, что рост у лишайников протекает очень медленно и длится иногда десятилетиями, а гормональную регуляцию, связывают, с достаточно быстро протекающими фризиологическими процессами. Однако можно говорить об определенном гормональном статусе, который фоормируется под действием природных факторов среды (освещенность, влажность и др.) при эпизодическом «пробуждении» лишайников и является необходимым для запуска и регуляции в них физиолого-биохимических процессов и, в конечном итоге, ростовых процессов.

Для оценки влияния фитогормонов на рост компонентов лишайника Physcia stellaris (L.) Nyl. были измерены размеры клеток водорослей и гифов гриба, полученные результаты занесли в таблицу 2. 
Таблица 2. Размеры компонентов лишайника Physcia stellaris (L.) Nyl.

\begin{tabular}{|c|l|c|c|}
\hline № & \multicolumn{1}{|c|}{ Место сбора } & $\begin{array}{c}\text { Клетки гифов гри- } \\
\text { ба, мкм }\end{array}$ & $\begin{array}{c}\text { Клетки водорослей, } \\
\text { мкм }^{3}\end{array}$ \\
\hline 1. & Альшеевский район & $41,6 \pm 5,1$ & $1767 \pm 207$ \\
\hline 2. & Ишимбайский район & $69,4 \pm 7,2$ & $2438 \pm 378$ \\
\hline
\end{tabular}

Согласно приведенным данным таблицы 2 видно, что размеры и объемы клеток у лишайников, выросших в разных условиях среды различны. Так наибольший размер клеток водорослей наблюдался у лишайников, собранных в Ишимбайском районе, их размер в среднем достигал $2438 \pm 378$ мкм $^{3}$. Так же установлено, что размеры фритобионта лишайников из Ишимбайского района $\left(2438 \pm 378\right.$ мкм $\left.^{3}\right)$ были больше, по сравнению с образцами из Альшеевского района $\left(1767 \pm 207\right.$ мкм $\left.^{3}\right)$. Такое различие, скорее всего, связано с природно-климатическими условиями (влажность, освещенность и т.д.) произрастания лишайников. Сравнивая размеры клеток водорослей с клетками гифов гриба можно сказать, что наибольшее угнетение процессов роста наблюдается у клеток фритобионта (табл. 2).

Таблица 3. Содержание гормонов в лишайниках Physcia stellaris (L.) Nyl. нг/г сухой массы

\begin{tabular}{|l|l|l|l|l|l|l|l|}
\hline \multirow{2}{*}{ № } & \multirow{2}{*}{ Место сбора } & \multirow{2}{*}{ ИУК } & \multirow{2}{*}{ АБК } & \multicolumn{4}{|l}{ Цитокинины } \\
\cline { 5 - 8 } & & & & Сумма & ZN & $Z \mathrm{R}$ & $\mathrm{Z}$ \\
\hline 1. & Альшеевский район & $34 \pm 4$ & $102 \pm 9$ & $96 \pm 10$ & $16 \pm 1,1$ & $26 \pm 2$ & $34 \pm 2,7$ \\
\hline 2. & Ишимбайский район & $43 \pm 3,6$ & $78 \pm 6$ & $71 \pm 9$ & $18 \pm 2$ & $38 \pm 2,3$ & $8 \pm 0,5$ \\
\hline
\end{tabular}

Примечание. ИУК - индолил-З-уксусная кислота, АБК - абсцизовая кислота, ZN - зеатиннуклеотид, ZR - зеатинрибозид, Z - зеатин.

В таблице 3 отражены данные о содержании гормонов ИУК, АБК и цитокининов (производных зеатина), определенных для оценки состояния гормональной системы лишайников Physcia stellaris (L.) Nyl., выросших в разных экологических условиях.

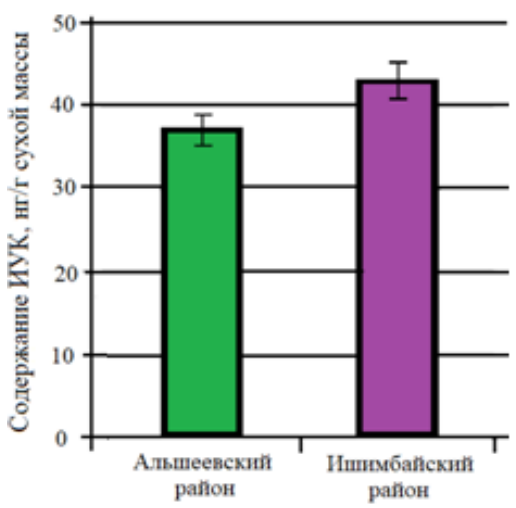

Pис. 1. Содержание ауксинов в лишайниках Physcia stellaris (L.) Nyl.

Наибольшее содержание фритогормона ИУК в лишайниках из двух указанных районов

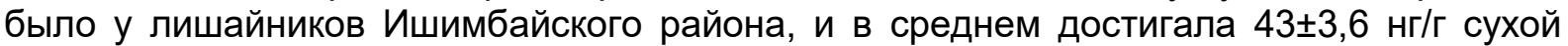
массы. по сравнению с лишайниками из Альшеевского района, где его содержание было в среднем $34 \pm 4$ нг/г сухой массы. Ауксины в растениях, под воздействием окружающей среды [5], стимулируют рост клеток путем растяжения [6], поэтому можно предположить, что у лишайников Ишимбайского района (горно-лесная зона) в периоды роста 
и развития содержание данного гормона было относительно высоко, что и привело к фрормированию наиболее крупных клеток гриба и водоросли (табл. 2).

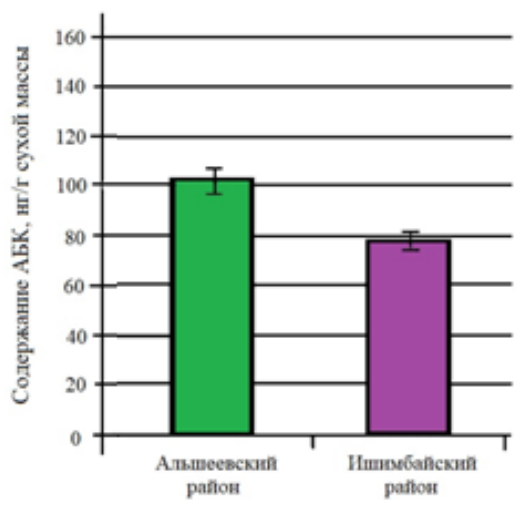

Рис. 2. Содержание АБК в лишайниках Physcia stellaris (L.) Nyl.

Концентрация фритогормона АБК как известно, увеличивается в результате понижения содержания воды в тканях растений [6], с чем возможно связано высокое содержание

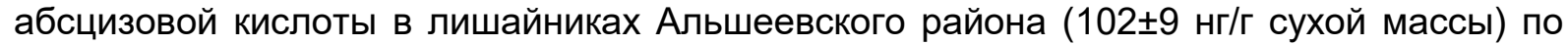

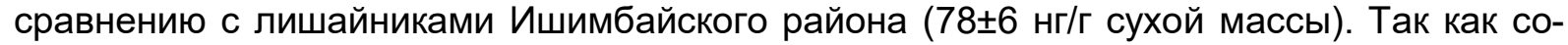
держание воды согласно таблице 1 в образцах лишайников из Альшеевского района $(20,3 \pm 2,46 \%)$ было в 2 раза ниже, чем в лишайниках Ишимбайского района $(46,4 \pm 6,02 \%)$, а содержание фритогормона АБК в 1,5 раза выше. Наличие достоверно высокого уровня содержания гормона АБК в образцах из Альшеевского района по сравнению с образцами Ишимбайского района (табл. 3), не оказало влияния на морфологические показатели лишайников (табл. 1), но возможно привело к развитию не больших по размеру клеток у лишайников (табл. 2).

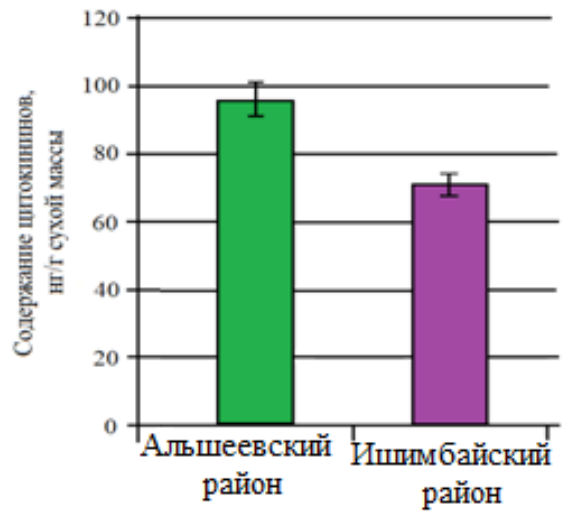

Рис. 3. Содержание суммы цитокининов в лишайниках Physcia stellaris (L.) Nyl.

Определение содержания общей суммы цитокининов в образцах лишайников показал, что их наибольшее количество содержится в лишайниках из Альшеевского района -

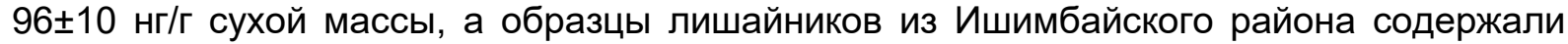
$71 \pm 9$ нг/г сухой массы цитокининов (табл. 2, рис. 3). Так как цитокинины стимулируют процесс деления клеток, то возможно, за счет этого сформировались внешние размеры талломов сопоставимые с ростовыми характеристиками лишайников из Ишимбайского района (табл. 1).

Таким образом, нами была установлена роль гормональной системы в регуляции ростовых процессов лишайников Physcia stellaris (L.) Nyl, в первую очередь через возможную регуляцию процессов клеточного деления и размеров клеток симбионтов. 
В адаптации растений к внешним условиям среды важную роль играют также флавоноиды [7]. Поэтому представило интерес установить какая взаимосвязь существует между содержанием фрлавоноидов, и их влиянием на рост лишайников в разных природно-климатических условиях.

Было определено количественное и качественное содержание фрлавоноидов в лишайнике Physcia stellaris (L.) Nyl. (табл. 4). Так высокое суммарное содержание фрлавоноидов на единицу массы было установлено в образцах из Ишимбайского района по сравнению с Альшеевским районом, где содержание фллаворноидов было меньше. Детальный анализ качественного состава фрлавоноидов показал, что в лишайниках из Ишимбайского района в высоких концентрациях содержаться нарингин, дигидрокверцетин и кверцетин. В образцах, полученных из Альшеевского района среди выше указанных фрлавоноидов с высокой концентрацией содержанию был рутин. Разный уровень содержания различных групп фрлавоноидов, вероятно, связан с особенностями процессов метаболизма френольных соединений [8].

По видовому содержанию соединений фенольной природы лидировали лишайники Ишимбайского района. В них было определено 128 видов флавоноидов, в образцах из Альшеевского района было обнаружено - 78 видов. Различия в количественном и качественном составе между образцами Ишимбайского и Альшеевского районов, вероятно, связаны с нахождением их в разных природных зонах - горно-лесной и лесостепной соответственно.

Таблица 4. Содержание фрлавоноидов и их антиоксидантный статус в Physcia stellaris произрастающих в разных условиях

\begin{tabular}{|c|c|c|c|c|c|c|c|}
\hline \multirow[b]{2}{*}{ Параметр } & \multicolumn{6}{|c|}{ Соединение } & \multirow{3}{*}{ 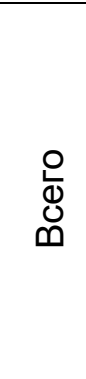 } \\
\hline & 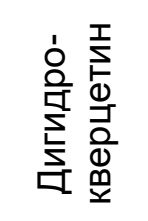 & 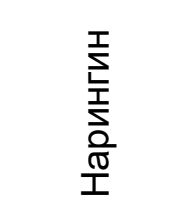 & $\underset{\square}{\stackrel{I}{\Sigma}}$ & 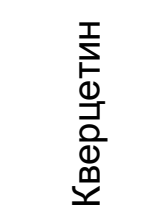 & 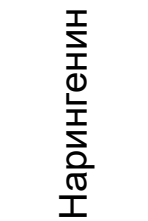 & $\begin{array}{l}\underset{I}{S} \\
\stackrel{D}{D} \\
\stackrel{M}{\theta}\end{array}$ & \\
\hline TEAC, MM & 1,9 & 0,5 & 2,4 & 4,7 & 1,53 & 0,8 & \\
\hline \multicolumn{8}{|c|}{ Альшеевский район } \\
\hline $\begin{array}{l}\text { Содержание, } \\
\text { мг/г сух массы }\end{array}$ & $6,5 \pm 0,7$ & $0,95 \pm 0,06$ & $7,5 \pm 0,8$ & $1,6 \pm 0,08$ & $2 \pm 0,3$ & 0 & 18,5 \\
\hline $\begin{array}{l}\text { Антиоксидант- } \\
\text { ный статус }\end{array}$ & 12,35 & 0,48 & 18 & 7,52 & 3,06 & 0 & 41,4 \\
\hline \multicolumn{8}{|c|}{ Ишимбайский район } \\
\hline $\begin{array}{l}\text { Содержание, } \\
\text { мг/г сух массы }\end{array}$ & $9,5 \pm 0,7$ & $7,5 \pm 0,5$ & $0,5 \pm 0,05$ & $7,55 \pm 0,8$ & $\begin{array}{c}0,7 \pm 0,0 \\
1\end{array}$ & $4,5 \pm 0,5$ & 30,2 \\
\hline $\begin{array}{l}\text { Антиоксидант- } \\
\text { ный статус }\end{array}$ & 18,05 & 3,75 & 1,2 & 35,49 & 1,07 & 3,6 & 63,1 \\
\hline
\end{tabular}

Примечание. Значение ТЕАС (тролокс-эквивалент (TEAC, trolox equivalent antioxidant capacity), мМ по Н.А. Тюкавкиной (2008).

Установлено, что разные виды лишайников, произрастающие в сходных условиях, имеют различный качественный и количественный состав фрлавоноидов $[9,10]$. Однако установление фрлавоноида на межпопуляционном уровне типичного для популяции лишайника Physcia stellaris (L.) Nyl., который позволил бы выявить достаточно четкую его связь с природно-климатическими условиями, нам не удалось обнаружить. 
Определение содержания фрлавоноидов в лишайнике позволило установить их роль в формирование общего антиоксидантного статуса (табл. 4), который можно использовать как показатель ответной реакции организма растения на стрессовою нагрузку [11].

Анализа фрормирования антиоксидантного статуса показал, что высокий антиоксидантный статус наблюдался в образцах лишайников из Ишимбайского района - 63,16, а минимальный был определен в лишайниках из Альшеевского района. В становлении высокого антиоксидантного статуса в лишайниках из Ишимбайского района важную роль играют кверцитин, дигидро-кверцетин и нарингенин, а в Альшеевском районе рутин и дигидро-кверцетин (табл. 4).

Таким образом, нами было установлено количественное и качественное разнообразие веществ френольной природы в образцах лишайников, собранных в горно-лесном, лесостепной зонах. В горно-лесной зоне (Ишимбайский район) было определено максимальное видовое разнообразие (128) и содержание фрлавоноидов в образцах, и был подсчитан самый высокий потенциальный антиоксидантный статус веществ фенольной природы.

Нам не удалось установить взаимосвязь между антиоксидантной активностью флавоноидов и внешними природно-климатическими условиями произрастания лишайников. Вероятно, наиболее значимой в реализации адаптационных механизмов является вариабельность состава и концентрации индивидуальных фенольных соединений в талломе лишайников под действием естественных фракторов.

\section{Литература}

1. Абдульманова С.Ю., Эктова С.Н. Изменение скорости роста кустисторазветвленных лишайников рода Cladonia в ходе пирогенных сукцессий на севере Западной Сибири. // Сибирский экологический журнал. 2015. №3. С 398-412

2. Gogala N. Regulation of mycorrhizal infection by hormonal fac-tors produced by hosts and fungi. // Experientia, 1991, 47:331-340

3. Pozo MJ, López-Ráez JA, Azcón-Aguilar C, García-Garrido JM (2015) Phytohormones as integrators of environmental signals in the regu-lation of mycorrhizal symbioses. // New Phytol 205:1431-1436

4. Santner A, Estelle M (2009) Recent advances and emerging trends inplant hormone signalling. Nature 459:1071-1078

5. Ott S., Krieg T., Spanier U., Schieleit P. Phytohormones in lichens with emphasis on ethylene biosynthesis and functional aspects on lichen symbiosis // Phyton Annales Rei Botanicae. 2001. Vol. 40, is. 3. PP. 83-94.

6. Веселов Д.С., Веселов С.Ю., Высоцкая Л.Б., Кудоярова Г.Р. Фархутдинов Р.Г. Гормоны растений: регуляция концентрации, связь с ростом и водным обменом. - М. Наука, 2007, 158 с.

7. Epstein E., Sagee O., Cohen JD., Garty J. Endogenous auxin and ethylene in the lichen Ramalina duriaei. // Plant Physiol. 1986;82: 1122-1125.

8. Запрометов М.Н. Фенольные соединения: распространение, метаболизм и функции в растениях. М.: Наука, 1993. 272 с.

9. Загоскина Н.В., Николаева Т.Н., Лапшин П.В., Заварзин А.А., Заварзина А.Г. Водорастворимые фенольные соединения у лишайников. // Микробиология. 2013. Т. 82. №4. C. $434-441$. 
10. Загоскина Н.В., Николаева Т.Н., Лапшин П.В., Заварзина А.Г., Заварзин А.А. О содержании фенольных соединений в различных видах лишайников Кольского полуострова. // Химия растительного сырья. 2011. №4. С. 245-249.

11. Щербаков А.В., Даутова Г.Р., Усманов И.Ю. Межпопуляционная изменчивость фрлавоноидов хелатирующего комплекса солодки Коржинского Glycyrrhiza Korshinskyi на Южном Урале. // Вестник Башкирского университета. 2014. Т. 19. №1. С. 67-74.

Influence of climatic conditions on the population of the lichen Physcia stellaris (L.) Nyl.

Z.R. Saitova *, R.G. Farkhutdinov

Bashkir State University, Russia, 450076 Ufa, street Zaki Validi, 32.

*Email: fleurzily@yandex.ru

To assess the impact of natural and climatic conditions on the population of the lichen Physcia stellaris (L.) Nyl. growing in various natural zones (mountain-forest and foreststeppe), an analysis of the morphometric parameters of lichen (weight, length, thallus area, number of apothecia and lobes), the size of its constituent components (photo- and phytobiont) was carried out, and the content of phytohormones was also determined. The analysis of the quantitative and qualitative composition of phenolic compounds in lichens, which contributed to the formation of the general antioxidant status, was carried out.

Keywords: lichens, phytohormones, flavonoids, antioxidant status 